Espacio, Tiempo y Forma, Serie II, Historia Antigua, t. 25, 2012, pp. 423-436

\title{
Sobre la condición latina y su onomástica: los ediles de Andelo
}

\author{
On the latin condition and its onomastic: \\ the aediles from Andelo
}

\author{
Estela GaRcía FERNÁNDEZ*
}

\begin{abstract}
RESUMEN
ABSTRACT

El presente artículo pretende demostrar la existencia de la condición latina y la necesidad de su introducción en el análisis onomástico referido a las ciudades del Occidente del Imperio, limitado habitualmente a la identificación de población romana o peregrina. El análisis de la onomástica de los ediles de Andelo podría indicar la condición latina

This article aims to demonstrate the existence of the Latin condition and the need for its implementation in the onomastic analysis of the cities of the Western Empire, which is usually limited to identifying cives Romani or peregrini. The onomastic analysis of Andelo aediles could indicate the Latin condition of these magistrates.
\end{abstract} de estos magistrados.

PALABRAS CLAVE

Onomástica latina, ius Latii, Hispania romana, Galia romana, Derecho romano.

\section{KEYWORDS}

Latin onomastic, ius Latii, Roman Spain, Roman Gaul, Roman right.

Recibido el 1 de septiembre de 2012. Aceptado el 21 de septiembre de 2012

Mais il y a une question plus importante qu'on ne prend pas assez en considération en traitant du problème des rapports entre la condition de droit et la dénomination: on doit distinguer aussi dans la population de l'Empire entre les cives Romani et les peregrini una troisième catégorie, celle des cives Latini.

Este texto de G. Alföldy pertenece a un conocido artículo publicado en 1966, «Notes sur la relation entre le droit de cité et la nomenclature dans l'Empire romain», donde el autor llamaba la atención sobre dos importantes cuestiones: la existencia de población de condición latina (cives Latini) en comunidades dotadas de tal derecho y la necesidad de emprender estudios onomásticos que estableciesen contextualmente los modos particulares de denominación de dicha pobla-

*Dpto. Historia Antigua, Facultad de Geografía e Historia, Universidad Complutense, C/Profesor Aranguren s/n, Madrid: estgarci@ghis.ucm.es 
ción. En dicho trabajo el autor, entre otras observaciones que no han perdido vigor, abogaba por una flexibilidad onomástica como propia de la condición latina, reconociendo dicha condición en individuos de variadas estructuras nominales ${ }^{1}$. Con independencia de las matizaciones que el desarrollo de análisis onomásticos locales pudieran introducir en las tesis de G.Alföldy, hoy en día adquieren éstas especial interés e importancia habida cuenta de la práctica desaparición de la población de condición latina en gran parte de los estudios onomásticos referidos al Occidente del Imperio romano. Contra toda evidencia, y no es precisamente la menor que los municipes (o coloni) no romanos de una comunidad latina difícilmente podrán ser «peregrinos» ${ }^{2}$, el análisis onomástico se reduce habitualmente a la identificación estatutaria de ciudadanos romanos o peregrinos, únicas categorías cuya existencia se reconoce.

Los importantes trabajos reunidos por M. Dondin-Payre y M.-T. RaepsaetCharlier son quizá el mejor ejemplo de esta ausencia y el referente actual de muchos otros análisis onomásticos realizados en distintos territorios del Imperio ${ }^{3}$. Dos ideas estrechamente conectadas constituyen la base de su trabajo: la inexistencia de población libre de condición latina y en consecuencia la reducción del análisis estatutario a la identificación de ciudadanos de condición romana o peregrina en toda ciudad dotada de ius Latii, ya sea colonia o municipio.

La defensa de la inexistencia de individuos libres de condición latina parte de una propuesta someramente presentada por F. Millar quien en 1977 negó la existencia de latinidad ingenua después de la guerra social y que fue aceptada posteriormente por A. Chastagnol. Resultaba de esta tesis que la condición jurídica disfrutada por la población de las comunidades con derecho latino sólo podía ser romana o peregrina. Las menciones expresas a latinos (incluso a latinos ingenuos) que se registraban en la legislación municipal y en otras fuentes jurídicas como en las Pauli Sententiae habían de ser entendidas como referencias a latinos junianos, la única latinidad existente a juicio de Millar después de la promulgación de la lex Iulia de civitate que hizo desaparecer a todos los latinos ingenuos de Italia, esto es, a los antiguos latinos coloniarios al convertirlos en ciudadanos romanos. Conviene tener presente que F. Millar le dedica a esta tesis un apéndice de apenas seis páginas en un libro, The Emperor in the Roman World, que consta de 635 (índices aparte) lo que indica que no pretendía tratar en profundidad el tema, que éste ocupa un lugar tangencial en su obra y sobre todo que no manifiesta un convencimiento rotundo de que determinadas menciones a Latini no hagan efectivamente

${ }^{1}$ ALFÖLDY, Geza, «Notes sur la relation entre le droit de cité et la monenclature dans l'Empire romain", Latomus, 25, (1966), pp. 37-57. El texto citado Ibid. p. 39.

2 Sobre esta imposibilidad se expresó G. Alföldy con mucha claridad al hacer referencia a la población del municipio latino de Rider en Dalmacia: Évidemment, les citoyens du municipe avant 212 ne pouvaient pas avoir un statut péregrin; par conséquent, il s'agit ici de cives Latini, Ibid. p. 55.

${ }^{3}$ DONDIN-PAYRE, Monique y RAEPSAET-CHARLIER, Marie-Thérèse, (eds.), Noms, Identités culturelles et Romanisation sous le Haut-Empire, Bruxelles, 2001. 
referencia a latinos ingenuos provinciales ${ }^{4}$. Las referencias expresas a la existencia de la condición latina ingenua en las Pauli Sententiae (por ejemplo ibid. 4.9.8 Latina ingenua, ius Quiritium consecuta, entre otros pasajes ${ }^{5}$ ), o las menciones a individuos de condición latina contenidos en las leyes flavias han sido discutidas pormenorizadamente en otras sedes a cuyas páginas remito por ser en exceso prolija y técnica la discusión ${ }^{6}$.

A mi modo de ver no deja de resultar paradójico que comunidades que poseen derecho latino ya sean municipios o colonias y cuyos habitantes son colectivamente calificados de latinos como ocurre con Latinorum Lucentum (Plinio NH III, 20) en la Hispania Citerior, Ruscino Latinorum (Plinio NHIV, 32) en la Galia Narbonense o las Latini iuris Euganeae gentes (NH III, 133) en los distritos Alpinos entre otras menciones, no cuenten entre sus habitantes con individuos que posean tal condición y todo el análisis estatutario se resuelva en decidir entre una condición peregrina o romana. De hecho $\mathrm{M}$. Humbert ya había señalado a propósito de la tesis de F. Millar que era inexacto afirmar que el concepto de Latinus no existía en el Imperio puesto que era definido incluso como la condicio de un pueblo (Latinae condicionis Centuripini, NH III, 91). Observando además este autor que el empleo del término Latini por Gayo (Inst. I, 79) para denominar a los latinos de su tiempo y la descripción de su status en el primer capítulo consagrado a la condición de las personas, daría a entender que la latinidad es algo más que un derecho de acceso a la ciudadanía romana?.

En estas páginas quisiera detenerme en algunas cuestiones relativas a la estructura onomástica y su interpretación jurídica. Siguiendo la senda marcada por A. Chastagnol se suele defender en los actuales estudios onomásticos que todos

${ }^{4}$ MILLAR, Fergus, The Emperor in the Roman World: 31 BC.-AD 337, Duckworth, 1977, pp. 630635. La génesis de la posición de A. Chastagnol en la propuesta de F. Millar la menciona el propio autor en «L'onomastique de tipe pérégrine dans les cités de la Gaule Narbonnaise», MEFRA 1022 , (1990), pp. 575-576. Asimismo DONDIN-PAYRE, M. y RAEPSAET-CHARLIER, M.-T., Op. Cit pp. II-IV.

${ }^{5}$ Los pasajes muy elocuentes de las Pauli Sententiae son los siguientes, además del citado en el texto: 2.21‥1: Si mulier ingenua, civisque Romana vel Latina...; Ibid. 4.9.8 Latina ingenua, ius Quiritium consecuta...; y asimismo 4.10.3. Todos ellos comentados por LÓPEZ BARJA DE QUIROGA, Pedro, «Latini y Latini luniani. De nuevo sobre IRNI, 72» Studia Historica. Historia Antigua, IX, (1991), pp. 53-54. Al autor le resulta sorprendente que F. Millar contemple la posibilidad de que la expresión Latina ingenua pueda referirse a la hija de una latina juniana, ya que en su opinión «si no se acepta otra latinitas personal que la juniana, difícilmente podría el hijo de un juniano acogerse a una civitas inexistente» (Ibid. p. 54).

${ }^{6}$ LÓPEZ BARJA DE QUIROGA, P., Op. Cit. pp. 51-60 realiza una crítica sólidamente argumentada desde una perspectiva jurídica a la propuesta de Millar y acepta con buenos argumentos el valor de los textos de las Pauli Sententiae a los que F. Millar niega valor aduciendo su procedencia tardía. También acepta la existencia de condición latina ingenua citando a P. López Barja de Quiroga y con argumentos adicionales, DARDAINE, Sylvie, «Les affranchis des cités dans les provinces de l'Occident Romain: statut, onomastique et nomenclature», en Ciudades privilegiadas en el Occidente Romano, J. GONZÁLEZ (ed.), Sevilla, 1999, pp. 214-216; asimismo GARCÍA FERNÁNDEZ, Estela, «Latinidad y onomástica en el Noroeste», en El bronce de El Picón (Pino de Oro). Procesos de cambio en el occidente de Hispania, SASTRE, Inés y BELTRÁN, Alejandro (eds.) Junta de Castilla y León, 2010, pp. 145-155.

7 HUMBERT, Michel, «Le droit latin impérial: cités latines ou citoyenneté latine?», KTEMA, 6, (1981), p. 209 n. 8. 
aquellos individuos que portan duo nomina (entendiendo por tal nomen y cognomen) o tria nomina han de ser identificados necesariamente como ciudadanos romanos, mientras que el grupo de los peregrinos estará constituido por aquella población que hace uso del nombre único más la filiación (o idiónimo más patronímico), si bien se identifican también como tales algunos individuos que portan estructuras bimembres con determinadas características ${ }^{8}$.

Estos criterios de identificación estatutaria no se adecuan sin embargo a las características que presenta el material epigráfico de aquellos territorios provinciales que combinan alto grado de romanización y presencia de derecho latino. Pienso en la provincia Bética, por ejemplo, que acoge como es sabido un elevado número de municipios de derecho latino (mayor que de comunidades romanas) cuyos ciudadanos utilizan un sistema de denominación personal plenamente romano (duo nomina o tria nomina), donde la onomástica de tipo peregrino es irrelevante y la existente tiene una datación anterior a la concesión de Vespasiano ${ }^{9}$. De hecho en ausencia de tribus y magistraturas no es posible diferenciar en la Bética a un ciudadano romano de aquel otro que carece de esta condición. Y como parece a su vez bastante improbable que en un municipio latino sea únicamente el siempre minoritario grupo formado por ciudadanos romanos el que dé cuenta de su existencia a través de la epigrafía (sobre todo cuando se observa en otras zonas de menor romanización que la población peregrina practica también el hábito epigráfico), es de esperar que un gran número de individuos atestiguados en el registro epigráfico bético sean de condición jurídica latina (y no peregrinos a la vista de sus tria nomina con gentilicios romanos) ${ }^{10}$. Otra cuestión será que puedan o no ser identificados.

Pero si esto es así en el caso de la Bética cabe sacar de este hecho una conclusión adicional. Es de esperar que la población de una provincia mayoritariamente latina ${ }^{11}$ y que de manera generalizada utiliza el tria nomina no haga uso del mismo de manera ilegal. Precisamente el celo mostrado por el emperador Claudio para evitar el uso fraudulento de los gentilicios romanos por personas de condición peregrina (peregrina condicio) ${ }^{12}$ está sugiriendo la imposibilidad de que unos pro-

${ }^{8}$ La identificación de los ciudadanos romanos con todos aquellos individuos que porten duo nomina o tria nomina está fuera de toda discusión para DONDIN-PAYRE, M. y RAEPSAET-CHARLIER, M.-T., Op. Cit. III-IV. Para el análisis de las restantes estructuras onomásticas y criterios de análisis, Ibid. IV-VIII y especialmente el exhaustivo y cuidado trabajo de DONDIN-PAYRE, M., «L'onomastique dans les cités de Gaule centrale (Bituriges Cubes, Éduens, Senons, Carnutes, Turons, Parisii)», Ibid. pp. 193-341, (se explicitan los criterios para identificar población peregrina, Ibid. pp. 259-283).

9 Así DARDAINE, S., Op. cit. pp. 213-214; asimismo GONZÁLEZ ROMÁN, C., «La lex Irnitana y la onomástica de los municipios flavios» Memorias de Historia Antigua, XXIII-XXIV, (2002-2003), p. 84 sobre la irrelevancia de la onomástica peregrina en la Bética.

${ }^{10}$ En el mismo sentido se pueden leer las reflexiones de DARDAINE, S., Op. Cit. pp. 213-214.

${ }^{11}$ Como es sabido los listados plinianos dejan ver la existencia de un alto número de comunidades que permanecían en condición peregrina antes de la concesión de ius Latii y que habrían de convertirse en época flavia en municipios latinos (a los que habría que añadir también los surgidos anteriormente a partir de época de Augusto).

${ }_{12}$ Tal es el caso de los Anauni atribuidos a Tridentum quienes en la creencia de que estaban en posesión de la ciudadanía romana incorporaron los gentilicios romanos a su onomástica, hecho que por practicado de antiguo tuvo que aceptar el emperador Claudio para no causar perjuicio al municipio ro- 
vinciales no autorizados legalmente para ello pudieran hacer uso habitual de la estructura onomástica romana y de los gentilicios que le son propios. El comportamiento onomástico de la población Bética apuntaría entonces a que la concesión de ius Latii haya podido ir acompañada de una autorización general para que la población de recién estrenada condición latina pudiera construir y utilizar la estructura trinominal romana, pudiendo para ello hacer uso de gentilicios de origen romano (o incluso indígena). De otra manera difícilmente podría explicarse a mi juicio el uso generalizado de estructuras onomásticas romanas por parte de la población de los numerosos municipios latinos de la provincia Bética.

A mi modo de ver el argumento de mayor peso empírico lo ha suministrado S. Dardaine quien ha demostrado el uso de estructuras onomásticas trimembres por personas de condición latina analizando la onomástica de aquellos libertos públicos manumitidos por magistrados de comunidades con derecho latino: así $C$. Publicius Fortunatus/ liber(t)us m(unicipii) F(lavii) Nerca[n(iensis)] (CIL II 2009) o [T.] Flavius Baeticus lib(ertus) reip(ublicae)/ Muniguensium (AE, 1972,254) entre otros ${ }^{13}$. Es importante señalar al respecto que el cap. 72 (De servis publicis manumittendis) de la ley de Irni establece claramente que los libertos públicos tendrán una condición latina plena (y no juniana): Qui ita munumissus liberve esse iussus erit, liber et Latinus esto, quaeve ita manumissa liberave esse iussa erit, libera et Latina esto, eique municipes municipi Flavi Irnitani sunto (cap. 72 II. 16-19) ${ }^{14}$. A la vista de esta

mano: nomina ea/quae habuerunt antea tanquam cives Romani, ita habere is permittam (CIL V 5050). De forma general sabemos por Suetonio que Claudio prohibió hacer uso de los gentilicios romanos a población de condición peregrina: peregrinae condicionis homines vetuit usurpare Romana nomina dumtaxat gentilicia (Suetonio, Claudio 25.7). Ya en la república la lex Papia de peregrinis instituyó una quaestio extraordinaria para expulsar de Roma a aquellos que se habían hecho pasar por ciudadanos romanos (Cic. De off. III.11.47). El uso de gentilicios romanos es de esperar que estuviera comprendido en la frase: Nam esse pro cive, qui civis nos sit rectum est non licere.

${ }^{13}$ DARDAINE, S., Op. Cit. pp. 225-227 proporciona una relación de documentos epigráficos provenientes de varias comunidades de Occidente donde se refleja el uso del tria nomina por los libertos públicos de distintas ciudades latinas. Así para Aquae Sextiae en la Narbonense Sex(tus) Publicius Antenor (CIL XII 523) o Ti(berius) Claudius Favor (Celeia CIL III 5227) o C. Publicius Asiaticus (Virunum CIL III, 4870) en sendos municipios del Norico. También T. Publicius Tertius de la colonia latina de Augusta Treverorum y que es incluido en la relación de ciudadanos romanos por RAEPSAET-CHARLIER, M.-T., "Caractéristique et particularités de l'onomastique trévire» en Noms Identités..... p. 384 podría ser considerado un liberto público de condición latina habida cuenta del carácter de colonia latina que posee su ciudad.

${ }_{14}$ Tengo presente las objeciones de FEAR, A. T., «Cives latini, servi publici and the Lex Irnitana», RIDA, 37, (1990), pp. 150-166 quien interpretó en el mismo sentido que Millar el capítulo 72 de ley de Irni referente a la manumisión de esclavos público. La objeción de mayor peso que aduce es el argumento cronológico ya que no es hasta el s.c. Neratianum que Adriano autoriza a las comunidades provinciales a manumitir esclavos públicos, siendo por tanto posterior a ley Irnitana. Esto significaría que antes de dicho emperador las comunidades provinciales sólo podían manumitir informalmente, es decir, sólo podrían conferir el status legal de Latini luniani. Pero se podría objetar que su razonamiento ha de ser aplicado a comunidades optimo iure que son las únicas que pueden conferir ciudadanía romana a sus esclavos públicos y dado que el tipo de ciudadanía que puede otorgar un municipio latino no es romana obviamente, sino latina, esta circunstancia explica que no sea necesario el consentimiento del gobernador provincial para que la colectividad pueda conceder una ciudadanía que en realidad es de segundo orden. También, LÓPEZ BARJA, P., Op..Cit. pp. 55-60 quien refuta la argumentación de A. T. Fear. Asimismo defiende DARDAINE, S., Op.Cit.. p. 217 que los libertos de las comunidades latinas son latinos de pleno derecho y no junianos (sobre sus objeciones a la posición de Fear Ibid. pp. 214-15). 
formulación jurídica parece concluyente la existencia de latinos de pleno derecho y no junianos en un municipio de tal derecho y de ahí la necesidad de encontrar criterios onomásticos que pudieran identificarlos en la documentación como proponía Alföldy.

Ahora bien, una autorización no significa imposición, a fin de cuentas la latinidad mantiene al individuo, salvo que desempeñe una magistratura, fuera del mundo de los administradores del sistema y de los beneficios directos del mismo. En aquellas zonas donde las tradiciones onomásticas locales están vivas y la romanización es menos intensa se producen tensiones y ajustes entre los arraigados modos de denominación indígenas y los romanos que se resuelven onomásticamente de un modo variado como observó G. Alföldy. Esto podría explicar los diferentes comportamientos onomásticos en ciudades de condición jurídica latina, ya sean de titulación colonial o municipal, asentadas en uno u otro territorio provincial.

Esto no significa defender una flexibilidad acrítica, sino la capacidad de adaptación de un expediente a las distintas tradiciones indígenas con las que entra en contacto como se demuestra en el pormenorizado trabajo realizado por M. DondinPayre, por ceñirme exclusivamente a la Galia Central, donde la autora observa por ejemplo en la creación de "gentilicios patronímicos" una adaptación sutil de dos tradiciones onomásticas, la local y la romana, o en palabras de la autora «les gentilices patronymiques de ce type concilient les deux civilisations» ${ }^{15}$.

Rechazar la existencia de población de condición latina en comunidades de las que se tiene constancia de concesión de ius Latii (y titulación colonial o municipal) en aras de la existencia únicamente de población romana o peregrina no parece que permita elaborar a la postre criterios más precisos de análisis onomástico en lo que respecta a la clasificación estatutaria de la población. De hecho no siempre resulta segura la identificación de individuos que portan una estructura onomástica bimembre con ciudadanos romanos, ni la onomástica peregrina responde como sería de esperar, a una estructura formada por un nombre único (idiónimo) más la filiación (patronímico), pues se incluyen también en este grupo estructuras bimembres formadas por un praenomen romano más un nombre individual que por referencia a la onomástica romana seria un cognomen, o estructuras binominales formadas por dos nombres únicos yuxtapuestos ${ }^{16}$. Por ejemplo $Q$. Caletedo ( $A E$ 1995 1067), Q. Caranto Endami f. (AE 1995 1066) procedentes de la colonia latina de Nemausos son clasificados entre la población peregrina de la colonia, y sin em-

${ }^{15}$ DONDIN-PAYRE, M., «L'onomastique ....», p. 244. En esta sección de su trabajo la autora ibid. pp. 243-252 analiza pormenorizadamente el sugerente fenómeno de la «patronimia» («patronymie») nombre que recibe la formación de un elemento de la nomenclatura onomástica de un hijo (en principio el gentilicio), a partir de un elemento de la nomenclatura de su padre. Como afirma la autora este uso se diferenciaría tanto de la práctica romana de transmitir sin modificación el gentilicio como de la indígena de cambiar de nombre de generación en generación (ibid. p. 243).

${ }^{16}$ Como ejemplo de estructuras binominales cuyos portadores se clasifican entre los peregrinos: Iulianus Crescens (CIL XIII 2726), Apronianus Saserus (CIL XIII 2912) o el eduo Cosuobnus Priscus Tatiri f. $(A E$ 1922, $14=$ =ILAfr 645=IAM 2, 508) eques del ala Tauriana entre otros, DONDIN-PAYRE, M., «L'onomastique.... pp. 273-283. 
bargo los ediles Sex(tus) Vetto C(aius) Pedo aed(iles) (CIL XII 4.190), magistrados aún en ejercicio y procedentes del territorio de la misma ciudad narbonense y con estructura onomástica similar a los anteriores en la que igualmente parece estar también ausente el nomen no les impide ser clasificados entre los ciudadanos romanos $^{17}$.

Se identifican como peregrinos entonces un grupo importante de estructuras bimembres en la idea de que en estos casos los elementos onomásticos no tienen el sentido estricto que tendrían en una nomenclatura ciudadana, es decir, serían préstamos carentes de función y significación. A pesar de la firme defensa de la idea de que la onomástica expresa un estatuto preciso ${ }^{18}$, se ha de recurrir en algunas circunstancias de difícil ubicación estatutaria al concepto de «romanización cultural» para dar cobertura a aquellas prácticas onomásticas en las que población, supuestamente peregrina, parece expresar su deseo de integrarse en el sistema del que están temporalmente excluidos utilizando estructuras nominales que en principio no le son propias. No implicaría este hábito un deseo de fingir una condición que no se posee, entre otras cosas porque las oligarquías ciudadanas vigilarían estrechamente cualquier intento de usurpación, sino un deseo de emulación mientras se espera la ratificación legal: la romanisation est là encoré culturelle, avant d'être entérinée par la loi ${ }^{19}$.

La introducción de la condición latina de cuya existencia da cuenta de un modo inequívoco la legislación municipal hispana ${ }^{20}$ permitiría a mi modo de ver desarrollar una mayor precisión en el análisis estatutario de la población, dar cabida a variadas circunstancias onomásticas e integrar de un modo más coherente la información literaria y jurídica disponible en el estudio de los procesos romanizadores. El latino no parece tener un sistema onomástico propio pero puede en principio estar autorizado para hacer uso del tria nomina romano (excepto la tribus) por las razones expuestas más arriba. Ahora bien, el mayor o menor arraigo de usos onomásticos de tradición local pueden incidir y condicionar la estructura onomástica a utilizar como con otra interpretación estatutaria han demostrado los estudios reunidos por M. Dondin-Payre y M.- T. Raepsaet-Charlier ya citados.

${ }^{17}$ Así CHRISTOL, MICHEL, «Le droit latin en Narbonnaise: I apport de I epigraphie (en particulier celle de la cité de Nimes)", en Les Inscriptions Latines de Gaule Narbonnaise, Nimes, 1989 , p.91 clasificó a ambos ediles, un caso similar al de Andelo, entre los individuos peregrinos. Sin embargo recientemente, según noticia de DONDIN-PAYRE, M., «L'onomastique....», p. 269, n. 209 el mismo autor los considera ciudadanos romanos.

18 DONDIN-PAYRE, M. y RAEPSAET-CHARLIER, M.-T. D, Op.cit p. II defienden firmemente la necesidad de no disociar el modo de denominación y el estatus cívico.

${ }^{19}$ DONDIN-PAYRE, M., «L'onomastique .... p. 217.

${ }^{20}$ La mención expresa a los latinos en la legislación flavia son las siguientes: sobre el voto de los incolae qui cives $R$ (omani) Latinive cives erunt, referido al derecho de voto en las elecciones locales (cap. 53 de la ley de Malaca), municeps qui Latinus erit, sobre la posibilidad de manumitir ante el dunviro que se concede a todo munícipe latino, que no romano (cap. 28 de las leyes de Irni y Salpensa) y liber et Latinus esto, en referencia a la condición latina plena y no juniana del esclavo público manumitido por el magistrado autorizado de un municipio latino (cap. 72 de la ley de Irni). 
La onomástica de los ediles de la ciudad vascona de Andelo (Mendigorría, Navarra) podría ser un buen ejemplo de esta adecuación a la tradición onomástica local que se observa en la población de las colonias y municipios de derecho latino cuando se asientan en territorios de menor romanización, tanto en lo que se refiere a estructura nominal como al origen de los gentilicios.

El texto del epígrafe, una placa de bronce en el que dos ediles realizan una dedicación a Apolo Augusto es el siguiente: Apollini / Aug(usto) / Sempronius Ca/rus Silvini f(ilius) / Lucretius Marti/alis Lucreti f(ilius) / aediles / d(e) s(ua) p(ecunia) f(aciendum) (...) $(H E p 1,1989,491=A E 1989,456)^{21}$

Las características onomásticas de ambos magistrados han sido puestas de relieve recientemente por E. Cantón quien ha señalado la filiación expresada a la manera indígena, es decir, mediante el cognomen o el nombre personal paterno y la utilización en el caso de Lucretius Martialis del nombre único del padre a modo de gentilicio. La autora advierte una segunda irregularidad al reparar que el nombre Lucretius utilizado por el padre del edil es a su vez un nomen romano, «la falta de tradición gentilicia llevaría al edil a adoptar como nomen el nombre peregrino de su padre que en el caso de Lucretius era un nomen empleado como nombre personal». Así siguiendo el proceso de construcción onomástica propuesto por dicha autora el uso irregular de un nomen romano, el mencionado Lucretius, lo realizaría la élite local aún sin derecho de ciudadanía con el ánimo de dar apariencia romana a su nombre, en alusión a la idea de «romanización cultural» mencionada anteriormente. Posteriormente la segunda generación, que ya ha obtenido la ciudadanía romana por vía magistratual, normalizaría este empleo irregular como es el caso del edil citado en el presente documento, Lucretius Martialis. Ambos ediles en la interpretación propuesta por la autora, que sigue de cerca las tesis francesas sobre onomástica, serían entonces ciudadanos romanos. Su estructura onomástica bimembre formada por un gentilicio romano más un cognomen así lo indicaría en la línea de otros muchos casos similares atestiguados en las provincias galas ${ }^{22}$.

Esta interpretación estatutaria sin embargo no es tan evidente a mi modo de ver pues no se repara en un hecho importante y es que ambos individuos no son

${ }^{21}$ La bibliografía sobre el bronce es abundante, la primera noticia del hallazgo la dio MEZQUíRIZ IRUJO, María Ángeles, «Placa de bronce con inscripción procedente de Andelos», TAN, 4, (1985), pp. 185-186; Ead. « Andelos: Secuencia estratigráfica y evolución cronológica», TAN, 17, (2004), 179-192; una reciente actualización sobre la ciudad, Ead. Andelo: ciudad romana, Navarra, 2009; asimismo, C. CASTILLO y J. Ma BAÑALES, «Epigrafía romana de Andión y su entorno», PV, 50, (1989), 521-531y VELAZA, Javier «La evolución de la ciudad romana de Andelo a la luz de los testimonios epigráficos», en Los orígenes de la ciudad en el Noroeste Hispánico. Actas del Congreso Internacional, Lugo 15-18 de mayo de 1996, Lugo pp. 635-637 entre otros autores. Agradezco una vez más al equipo de Hispania Epigraphica (Hep) las facilidades dadas para consultar sus fondos epigráficos y bibliográficos.

${ }^{22}$ CANTÓN SERRANO, Esther, «Onomástica y organización social de los Vascones» en Los Vascones de las fuentes antiguas: en torno a una etnia de la Antigüedad penínsular, J. ANDREU PINTADO (ed.), collec. INSTRUMENTA, 32, Barcelona, 2009, pp. 423-455 donde realiza un análisis global de toda la epigrafía vascona; aquí concretamente pp. 434-435. Para la autora «todos los individuos en posesión de un nomen romano cumpliendo la función de nombre gentilicio deberían ser en principio considerados ciudadanos» (Ibid. p. 437). Asimismo RAMíREZ SÁDABA, J.L., «La romanización de los vascones: el paradigma de los Andelonenses»en III Congreso de Historia de Navarra, Pamplona, 1998, pp. 1-17. 
ex-magistrados, sino ediles en el ejercicio de su magistratura y por tanto carentes de la ciudadanía romana que sólo posteriormente habrán de obtener por vía magistratual como establece el ius Latii y la legislación flavia. Esta es también la interpretación de E. Ortiz de Urbina para quien ambos ediles «concluidas sus atribuciones locales», es decir, la edilidad que están desempeñando en el epígrafe serían adscritos a la tribus Quirina y habrían de exhibir en realizaciones epigráficas posteriores «junto con sus tria nomina, esta precisa indicación de que, además de ser cives selectos de su comunidad cívica, formaban parte del populus Romanus, la ciudadanía superior dentro del Imperio romano»23.

Cabe observar también que la falta de praenomen (y de tribus) en la onomástica de los dos ediles abundaría en la condición no romana de los mismos. Aunque en principio la ausencia de praenomen no es un criterio decisivo para negar la ciudadanía romana a un individuo dada la progresiva caída en uso del mismo desde finales del I, en el caso que nos ocupa el carácter oficial y solemne que adquiere una dedicación a Apolo Augusto grabada en bronce realizada por unos magistrados en ejercicio permite esperar el uso de una onomástica completa en caso de que ésta se poseyera ${ }^{24}$.

La estructura onomástica de ambas ediles merece una atención más detenida. En territorios donde es detectable una mayor incidencia de las tradiciones indígenas, la filiación se indica con frecuencia a través del nombre único del padre colocada generalmente después del cognomen. Así ocurre, como se ha indicado, en el caso de estos dos ediles, tanto Martialis como Carus se declaran hijos respectivamente de Silvinus y de Lucretius. Estos dos últimos nombres suelen entenderse habitualmente como nombres únicos o idiónimos, lo que indicaría que entre padre

23 ORTIZ DE URBINA, Estíbaliz, «La proyección de la élite de los Vascones en época romana. Representación local, provincial y estatal». en Los Vascones de las fuentes antiguas: en torno a una etnia de la Antigüedad penínsular, J. ANDREU PINTADO (ed.) collec. INSTRUMENTA 32 Barcelona 2009, pp. 466-67. Tampoco cabe pensar que ambos ediles tuvieran la ciudadanía romana antes de desempeñar el cargo porque con dicha magistratura se inicia generalmente la carrera magistratual y se accede joven a la misma. De hecho como ha estudiado PÉREZ ZURITA, Antonio David, La Edilidad y las élites locales en la Hispania romana, Córdoba, 2011, la edilidad para la mayor parte de los notables hispanos supuso el primer puesto de responsabilidad en la administración (Ibid, p. 286 y pp. 286-312 donde se puede ver una relación exhaustiva de las carreras magistratuales de los ediles en las distintas provincias de Hispania; es de interés señalar que únicamente se registra un caso proveniente de Emérita $(H e p 4,162)$ donde la cuestura figura antes de la edilidad Ibid. p. 295). En relación a la edad de los ediles fallecidos registrada epigráficamente afirma el autor que «se trata casi siempre de individuos jóvenes que debían estar comenzado a desarrollar el cursus honorum local» (Ibid. p. 295).

${ }^{24}$ Una dedicación similar a Apolo salvo en la importante circunstancia que corresponde a un ex magistrado, ciudadano romano por tanto y no a un edil en ejercicio de su cargo, se documenta en Igabrum: Apollini Aug(usto) / municipii Igabrensis / beneficio / Imp(eratoris) Caesaris Aug(usti) Vespasiani / c(ivitatem) R(omanam) c(onsecutus) cum suis per hono[r]em / Vespasiano VI co(n)s(ule) / M(arcus) Aelius M(arci) fil(ius) Niger aed(ilis) / d(edit) d(edicavit) (CIL II/2 5, 308; HEp 1, 1989, 244 ; 75 d.C.). En este caso el edil que se declara ciudadano romano en virtud del cargo desempeñado no indica la tribus pero sí una onomástica completa y una filiación romana. Cabe observar que en dedicaciones similares halladas en la propia Igabrum y en Cisimbrium la tribus Quirina la indican aquellos magistrados que dicen haber desempeñado el dunvirado (para Igabrum AfrRom-16-1-148; para Cisimbrium CIL II/2 291-Hep 1, 292; CIL II/ 2 - Hep 1, 293). Sobre el valor de estos documentos para el estudio de la municipalización flavia, STYLOW, A. U. «Apuntes sobre epigrafía de época flavia», Gerión, 4, (1986), pp. 290-303. 
e hijo se ha producido un cambio de estatus: de un padre peregrino a un hijo que ha accedido a la promoción como indicaría la posesión de nomen y cognomen. Sin embargo M. Dondin-Payre ha observado que en los casos en que el nombre del padre es un cognomen y no un gentilicio y aquél se coloca al final de los nombres del hijo como ocurre en la onomástica de Sempronius Carus, no podemos estar seguros de que el padre posea simplemente un nombre único y que se pueda defender entonces una promoción estatutaria en el caso del hijo. Para la mencionada autora este fenómeno es resultado de la convergencia de formas indígenas de mención del padre y de la contracción de la nomenclatura ciudadana con el fin de evitar la repetición del gentilicio ${ }^{25}$. De este modo podría esperarse que la onomástica del padre del primer edil pudiera ser la característica no de un individuo de condición peregrina sino bimembre (Sempronius) Silvinus y por tanto propia de un individuo estatutariamente promocionado ${ }^{26}$.

En el caso de Lucretius Martialis estamos ante una circunstancia quizá algo más compleja puesto que el patronímico del edil es un nomen, Lucretius, que coincide a su vez con el propio nomen del magistrado. Éste podría entenderse en principio como un nombre latino utilizado a modo de nombre único del padre, pero el contexto del epígrafe sugiere que la estructura onomástica podría ser más compleja. Si se renuncia a considerar Lucretius un nombre único, cabe pensar inicialmente que al igual que Silvinus podría estar desempeñando la función de cognomen en la onomástica del padre (uso que está registrado en la documentación) ${ }^{27}$. Sin embargo esta posibilidad obligaría a suponer una construcción onomástica del padre formada por dos nomina similares, o bien un cambio de gentilicio de padre a hijo, uso muy frecuente en las Galias pero no registrado en la zona ${ }^{28}$. Quizá sea preferible pensar en lo que el propio epígrafe indica, esto es, la

${ }^{25}$ DONDIN-PAYRE, M., «L'onomastique.... , pp. 215-216 donde analiza varios casos entre ellos el de Corn]elius Mag[nus ?] Atepomari [f.], curator senon o Sex.Gabinius Censorinus Dagob[i]ti [f.] que realiza una dedicación a Mercurio. A pesar del carácter de nombre celta único del padre no cree la autora fundado proponer una promoción cívica para los hijos, lo que se traduce en que padre e hijo tendrían el mismo status. Precisamente en Hispania parecen documentarse más profusamente este tipo de casos por ejemplo Val(erius) · C[at/u]ro · Sa[t]/eili f AE 1966, $178=R A P 165$ o lulia $\bullet$ An/nia • Tan/gini [•] f(ilia) AE 1967, 211; CPILC 511 entre otros muchos indicados por la autora, Ibid. p. 216 n. 78. También CIPRÉS, Pilar, «La onomástica de las inscripciones romanas del País Vasco. Estructura del nombre personal y estatuto jurídico», Velia, 23, (2006) pp. 114-116 contempla esta posibilidad en algunos casos registrados en la epigrafía romana del País Vasco. Asimismo CANTÓN SERRANO, Esther, Op. Cit. p. 430 contempla esta posibilidad en algunos casos, pero no la señala para los ediles de Andelo.

26 CANTÓN SERRANO, E,. Op. Cit. pp. 448-449 interpreta en el mismo sentido algunos casos de la onomástica vascona (ERZ, 51 y 3; CIL II, 2967 y 2963).

${ }^{27}$ Aunque no parece frecuente el uso de Lucretius como cognomen está documentado por ejemplo en Ipsca donde un ciudadano romano se denomina C(aio) Sempronio C(ai) f(ilio) Quir(ina) Lucretio Salviano (CIL II 2/5 391).

${ }^{28}$ CANTÓN, E., op. cit. p. 441. Se podría hipotetizar entonces un Lucretius Lucretus, pues este cognomen está atestiguado en IRC IV, 144 y en CIL II 2/5 391 podría leerse también Lucretus. Quisiera agradecer a Joaquín Gómez-Pantoja estas dos últimas referencias y su amable disposición a atender mis consultas. Encontramos por ejemplo una repetición de elementos onomásticos a modo de nomen y cognomen por ejemplo en CIL XIII, 4207 donde se registran, Sacratius Sacerianus, Sacratius Sacratius y Sacratius Sacrius, sobre este epígrafe, CHASTAGNOL, André, «Les changements de gentilice dans les familles romanisées en milieu de tradition celtique», en La Gaule romaine et le droit latin, Lyon, 1995, pp. 173-174. 
expresión de la filiación a través del nomen. Este uso se encuentra documentado con cierta regularidad. Así: Semproni/us Talav(u)s / Semproni/[6] (Peñalba de Castro, Clunia $A E$ 1988, 799), [Lu]cretia R/ogata Luc/reti f[il(ia)] (Mauritania Cesariense $A E$ 2002, 1700) o por ejemplo Sempron/io Severo / Semproni / filio an(norum) $X V / f($ ilio) p(ientissimo) f(aciendum) c(uravit) /(Lara de los Infantes CIL 2, $5802=$ ERLara 00066). Este último epígrafe es de especial interés porque podría demostrar el recurso al nomen para indicar la filiación sin necesidad de convertirlo en nombre único del padre. Si el joven, Sempronius Severus, posee duo nomina ha de portarlo igualmente su padre de quien lo habría heredado, aunque la economía del texto no lo explicite. Dada la corta edad del hijo no es posible que su onomástica pueda deberse a un posible acceso a la ciudadanía romana por vía magistratual, ni a ninguna otra circunstancia reglada. En este caso no hay motivo para pensar en un cambio de estatus entre padre e hijo, ya que ambos poseerían la misma estructura onomástica binominal, faltando únicamente el cognomen del padre. Esta podría ser también la circunstancia de Lucretius Martialis de cuyo padre tan sólo conoceríamos su nomen y no su cognomen como suele ser más habitual. En estos contextos quizá la utilización del gentilicio (romano) como filiación pudiera ser entendido como un elemento de prestigio que podría estar indicando el carácter no peregrino de la familia y el acceso a una nueva condición jurídica.

Además de las características específicas de la onomástica de ambos ediles pueden añadirse dos circunstancias significativas: la promoción de la ciudad y la cronología atribuida al bronce. Aunque Andelo no cuenta con la prueba irrefutable de su condición municipal, se acepta normalmente su condición de ciudad promocionada en virtud del edicto de latinidad de Vespasiano como sugiere no sólo la presencia de la edilidad, sino también el propio registro arqueológico ${ }^{29}$. De este modo los ediles realizaron su dedicación a Apolo cuando la comunidad era ya un municipio latino, puesto que el bronce se ubica cronológicamente en época antonina, (o bien entre Domiciano y los antoninos) ${ }^{30}$.

${ }^{29}$ Para ANDREU PINTADO, Javier, «Ciudad y Territorio en el solar de los vascones en época romana» en Navarra en la Antigüedad. Propuesta de actualización, Navarra, 2006, pp. 182-183 es «a todas luces indudable» la condición de municipio Flavio de Andelo, ciudad que vive su esplendor en época de Trajano-Adriano en que se remodela su urbanismo y surgen abundantes y lujosas villas; Id, Edictum, Municipium y Lex: Hispania en época Flavia (69-96 d.C.,) Oxford, 2004, ubica a Andelo entre los municipios flavios del conventus caersaraugutano p. 147 y 151 donde señala a modo de indicadores de tal condición, la mención de dichos ediles y el «excepcional despegue urbanístico, con construcción de muralla y parte del foro" Sobre los efectos municipalizadores de las medidas flavias, Ibid. pp. 9-14 y 115-119, y sobre los procesos de monumentalización y munificencia de las élites Ibid. pp. 169-180. Sobre el despegue urbanístico de Andelo MEZQUÍRIZ, Ma A «La ciudad de Andelos. Secuencia estratigráfica y evolución cronológica» PV , 7, 513-530; ANDREU PINTADO, Javier, «Algunas consideraciones sobre las ciudades del territorio vascón y su proceso de monumentalización», Espacio, Tiempo y Forma II Historia Antigua 17-18, (2004-2005), pp. 266-269. Asimismo VELAZA, Javier, Op. Cit., pp. 623642. A su vez defendiendo un planteamiento que disocia la concesión de ius Latii y la adquisición de titulatura municipal, ORTIZ DE URBINA, Estíbaliz. Las comunidades hispanas y el derecho latino, Vitoria, 2000, p. 145 para el caso concreto de Andelo.

30 Sobre la datación entre los principados de Domiciano y Adriano, MEZQUÍRIZ, Mª A., «Placa de Bronce....p. 186 ; Ortiz de Urbina, E. Las comunidades hispanas..., p. 145; Principado de Trajano o 
Ahora bien, ambos ediles no son ciudadanos romanos o al menos no se puede proponer que lo sean por vía magistratual ya que están desempeñando el cargo en el momento en que se erige el epígrafe, ni tampoco la onomástica permite hablar con seguridad de un cambio estatutario de padres a hijos para defender en estos últimos un acceso a la civitas per honorem, por el contrario es muy probable que los padres ya portasen duo nomina y los gentilicios romanos de que hacen gala los ediles. Y precisamente estas dos características de su onomástica, estructura y gentilicios romanos, impiden ubicarlos a su vez entre la población peregrina. Ni romanos, ni peregrinos por tanto. Su onomástica podría ser entonces la propia de unos munícipes de condición latina al igual que sus padres de quienes heredaron los gentilicios respectivos. Los habitantes de Andelo una vez recibido el ius Latii iniciarían el proceso de acomodo de su onomástica a estructuras trinominales que su nueva condición les autoriza a poseer. En este proceso habrán de converger tradiciones onomásticas locales y romanas como M. Dondin-Payre ha demostrado que ocurrió en la Galia central lo que se traduciría en la creación de fórmulas nominales no estrictamente romanas. La condición latina, que no la romana es la que daría cobertura jurídica a estas variantes onomásticas propias de una ciudadanía de segundo orden y que como tal había de ser menos exigente respecto a la precisa expresión de su status.

Aunque el expediente municipal latino sea "conceptuellement monstrueux" como lo definió $\mathrm{M}$. Humbert ${ }^{31}$, sigue siendo un contrasentido jurídico hablar de munícipes peregrinos y un error prescindir de la existencia de población latina en comunidades con ius Latii. Si Andelo es un municipio latino, sus ediles todavía no romanos, a la vista de las peculiaridades de su onomástica y de su circunstancia magistratual, han de poseer la condición que comparten con sus conciudadanos, y por tanto serían latinos al igual que los cives Latini procedentes de ciudades de similar derecho cuya capacidad de voto establece el cap. 53 de la lex Malacitana ${ }^{32}$.

Adriano PÉREZ ZURITA, A. D., Op. Cit. p. 498 nํs 60-61. Sin embargo la propuesta de VELAZA, J. Op. Cit. p. 637 de atribuir una datación flavia al epígrafe (datación aceptada como posible por ANDREU PINTADO, J. «Algunas consideraciones.... pp. 275-276 y n. 127) podría permitirnos hipotizar que ambos ediles pudieran ser precisamente los primeros magistrados de Andelo en desempeñar dicho cargo y como tales habrían sido probablemente nombrados directamente, circunstancia que con mucha verosimilitud propone STYLOW, A.U. Op. Cit. p. 299 n. 30 para Marcus Aelius Niger edil de Igabrum (CIL II/2 5, 308; HEp 1, 1989, 244 supra n. 24).

${ }^{31}$ HUMBERT, Michel, Municeps et Municipium: définition et histoire en Gli Statuti Municipali, L. Capogrossi Colognesi y E. Gabba (a cura di), Pavia, 2006, p. 29. Este autor contempla la posibilidad de que Roma haya vacilado al calificar de municipium una ciudad desprovista de civitas Romana denominando oppidum Latinum a esta etapa provisional, vacilación que a su juicio desaparecería ya con Claudio cuando se regulariza la titulatura municipal para las comunidades con ius Latii (Ibid. pp. 28-29 y n. 48). De todos modos aunque la vacilación pudiera ser asumible para la imposición de una titulatura municipal, los títulos coloniales que testimonian las ciudades latinas de la Galia Narbonense es a mi modo de ver un argumento importante para defender que no hubo comunidades latinas sin una precisa calificación administrativa, bien sea colonial o municipal.

${ }^{32}$ En cualquier caso si no se acepta la existencia de latinos el análisis onomástico habría que prever al menos la existencia de latinos de condición liberta juniana cuya existencia se defiende para poder explicar la expresión municeps municipi Flavi Salpensani, qui Latinus erit (cap. 28). 
Es cierto que se suele objetar que la concesión de ius Latii no convierte necesariamente a una comunidad en municipio o en colonia como defendía A. Chastagnol, pero también es verdad que este autor afirmó que el título administrativo sólo aparecería cuando se concedía a título de privilegio suplementario ${ }^{33}$. Cabe pensar entonces que todas aquellas comunidades que tienen documentada su condición colonial o municipal han recibido dicho privilegio, como Nemausos por ejemplo o Augusta Treverorum y tantas otras ciudades. Pues bien, en mucho estudios onomásticos no se lee una sola reflexión sobre la posibilidad de que si un oppidum Latinum o una civitas Latina (siguiendo la interpretación francesa) adquiere una titulación administrativa precisa en virtud de la concesión de un «privilége supplémentaire" y se transforme en municipio o colonia este hecho pueda de algún modo modificar también la condición estatutaria de su población, como sería de esperar. Sin embargo tanto en una como en otra circunstancia sólo se reconoce la existencia de ciudadanos romanos y peregrinos sin que el hecho a mi modo de ver importante de que un oppidum Latinum se convierta en colonia o municipio parezca afectar ni lo más mínimo a la condición estatutaria de sus ciudadanos.

Por ello me parece necesario recuperar la propuesta de G. Alföldy que reconoce la existencia de población de condición latina y defiende que su denominación puede corresponder a construcciones onomásticas de peregrinos o de romanos, ya que violenta mucho menos la dinámica jurídica de funcionamiento del estado romano, es más coherente con la información que suministra la documentación (no sólo epigráfica, sino también literaria y jurídica) y sobre todo permite ensayar una explicación global capaz de integrar distintos ámbitos territoriales o culturales. Las comunidades latinas son menos uniformes que las romanas como demuestra el fuerte contraste que puede existir en el comportamiento epigráfico de unas y otras. Como señala asimismo J. Andreu la desigual incidencia del sistema onomástico en las distintas comunidades latinas nos está informando sobre cómo el ius Latii se fue progresivamente adaptando a las áreas en que se iba implantando. Y del mismo modo que la organización territorial no fue uniforme, tampoco lo fue el comportamiento onomástico que se adecuó a los usos vigentes en cada zona en el momento de la extensión del derecho latino ${ }^{34}$. Por esta ductilidad en muchos de sus aspectos el municipio latino fue definido por M. Humbert como un merveilleux outil de romanisation douce.

\footnotetext{
${ }^{33}$ CHASTAGNOL, André, «A propos du droit latin provincial», lura, 38, (1987) p. 6.

${ }^{34}$ ANDREU PINTADO, J. Edictum...., pp. 139.
} 
